\title{
Introducing the Lancaster Postgraduate Statistics Centre - a Centre of Excellence in Teaching and Learning (CETL)
}

\author{
Bev Abram \\ Department of Mathematics and Statistics \\ Lancaster University \\ b.abram@lancaster.ac.uk
}

Postgraduate Statistics Centre

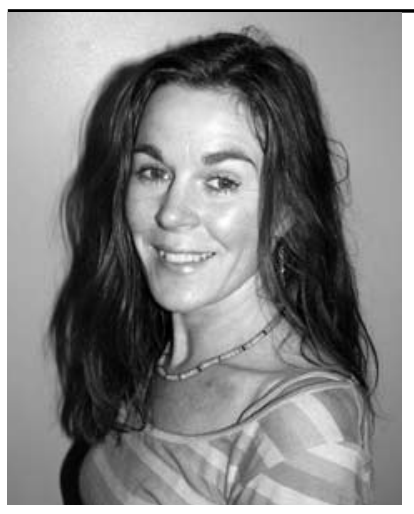

Brian Francis

Centre for Applied Statistics

Lancaster University

b.francis@lancaster.ac.uk

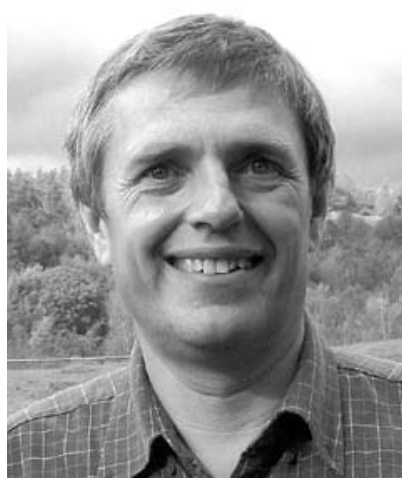

In the spring of 2005, the University of Lancaster was successful in winning a $£ 4.85$ million bid to fund a Centre of Excellence in Teaching and Learning (CETL). In common with other CETLs, the Lancaster CETL has the core aim of achieving excellence in teaching, however our specific focus on the development of postgraduate statistics taught both within the discipline of statistics and more broadly in other disciplines is more unique. The award is partially funding a $£ 3.3$ million building, the Postgraduate Statistics Centre (PSC), to expand the postgraduate activities of the department and will provide state of the art new teaching spaces for teaching statistics courses. In addition to this, funding has provided the department with several new members of staff and will allow a range of new resources to be developed within the centre. This article will give a general overview of the PSC and will discuss the main aims and objectives of the project followed by a brief summary of our achievements to date.

\section{Background}

The Statistics Department at Lancaster, already one of the UK's largest statistics research groups is a natural base for a flagship CETL in this discipline. The quality of statistics research at Lancaster is world class (RAE Grade $6^{*}$ ) and the research and teaching interests of the group are both diverse and at the interface between theory and applications. A unique strength of the group is the breadth and depth of collaborative research and teaching with Medicine, Social Science, Finance, Biology, Veterinary and Environmental Science, Management Science and other areas of Mathematics.

The PSC bid emphasised the belief that research quality and research-led teaching is crucial in teaching postgraduate statistics specialists. Well-trained Masters students will produce both a rich source of doctoral students in statistics and highly trained research statisticians to counteract the current shortage of young statisticians in both the public and private employment sectors, a national problem that was highlighted in the 2004 International Review of Mathematics.

The overarching aim of the PSC is to achieve excellence in postgraduate teaching in statistics, both to statisticians and non-statisticians. The applied focus of the Statistics Group makes these twin tasks mutually reinforcing. The project builds upon existing excellence already achieved within the group by using our long-established short course programme, which has a traditional strong practical emphasis in skills acquisition and on data interpretation, as a baseline for innovation, expansion and improvement.

\section{Aims and Objectives}

The main aims and objectives of the PSC can be summarised as follows : 
- To provide a state of the art teaching space and an inspirational environment where postgraduate students and staff can interact and discuss ideas.

- To achieve and to secure our position as the leading training centre for postgraduates in the UK by providing a regional, national and international centre of excellence in the postgraduate training and development of statisticians.

- To motivate, encourage and disseminate quantitative inquiry-led training for disciplines in the natural, social and management sciences, producing students who are enthusiastic and knowledgeable about the quantitative aspects of their discipline.

- To give Lancaster-trained postgraduate students quantitative skills which will influence and enhance their approach to research and will generate highly employable graduates.

- To extend and disseminate innovative and excellent teaching practice to partner departments by collaborating with colleagues to motivate and encourage topical and relevant inquiry-led research.

- To reward existing excellence in postgraduate teaching through improved facilities and increased personal time for course development, experimentation in new approaches to teaching, and to increase the possibilities for career development of staff working in this area.

We are implementing these objectives by engaging in a range of activities which include funding the new building, developing a range of courses and by developing a regional role in the training of statisticians and skilled quantitative researchers.

\section{Our Achievements to date}

\section{The PSC staff}

The CETL award has enabled the Lancaster Statistics group to expand by the creation of three new lectureships in the areas of Medical Statistics, Applied Statistics and Social Statistics. These appointments permit buy out time for other staff in the department, allowing them to spend time researching new teaching methods to both improve existing postgraduate courses and to develop new courses. In addition to this, the appointment of an administrator, a web officer and a computer technician provides support for pedagogic research and for experimenting and exploring new technologies and novel approaches to teaching statistics.

We are also delighted to report the recent appointment of a new Director for the Centre, Dr Gill Lancaster. Currently, Gill is Deputy Director of the Centre for Medical Statistics and Health Evaluation at Liverpool University and will take up her post at the PSC in May 2007.
Teaching rewards are being used to fund staff visits to other institutions and to attend teaching workshops to enhance and improve their teaching skills. New lecturers and postgraduate students, who are involved in teaching, are encouraged to enrol on courses provided by the university that will contribute to the Certificate in Academic Practice award. Staff have the opportunity to apply for funds to attend conferences, workshops and seminars that contribute towards their continued professional development.

\section{The New Building}

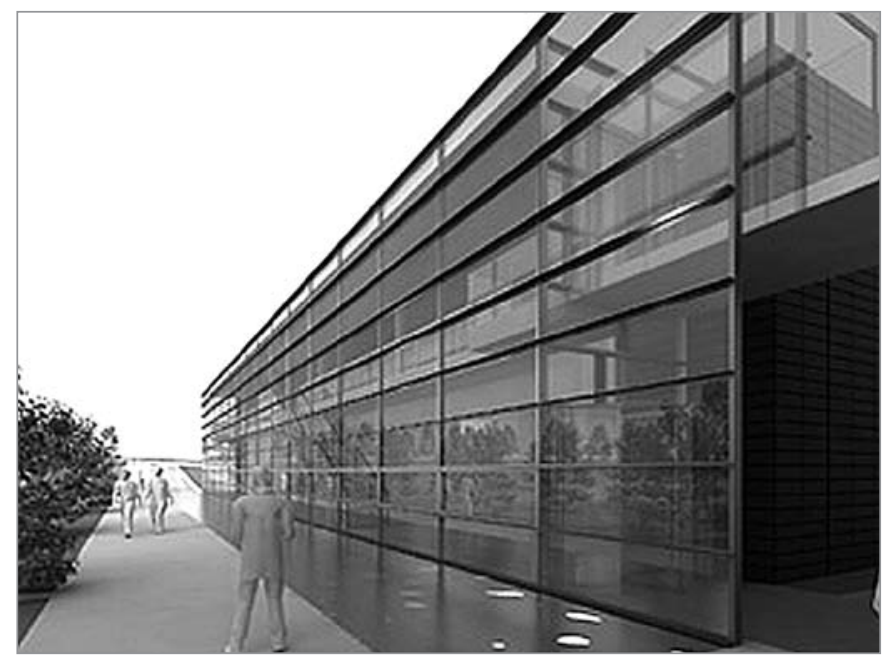

Fig 1 - The Postgraduate Statistics Centre

The new PSC building is currently under construction and is due to be completed by mid-November 2007. The architects are John McAslan and Partners, who have been involved on many high-profile projects including the recently restored London Roundhouse. Our brief to the architect was for a building full of light which will attract postgraduate students and staff to meet informally and allow high degrees of interaction. This is in contrast to the current space occupied by the department with narrow corridors and little interaction space. McAslan have designed a radical building which is aiming for the highest level of environmental quality.

The PSC is an innovative building, both from an educational and architectural viewpoint. On the ground floor, there will be a much needed teaching space for postgraduate statistics courses. In addition, since we have recently been designated as an ESRC Regional Training Centre, we will both run our own short courses and host courses provided by experts from other institutions from this new teaching space. There will be a 50-seat lecture theatre with automatic digital video recording and two large computer rooms. Another of the rooms will contain an access grid node, to allow distance learning courses to be given online to students in other universities.

On the first floor, there will be open areas for MSc students and staff to meet together with learning zones where postgraduate students and staff can relax 
and discuss work. A consultancy suite will provide one to one mentoring to postgraduate students from other disciplines, as well as providing training opportunities to our own students. A glass bridge will provide a link between the new building and the old department.

\section{Teaching Activity}

The PSC is involved in three main areas of statistics teaching. Firstly we are improving and expanding our MSc programme for statistics specialists. Secondly, in collaboration with other university departments, we are developing new MSc statistical modules and are upgrading the statistical components of existing modules. Finally, we our expanding our short course programme and statistical consultancy service.

\section{(i) Course Improvement and Development}

Prior to the CETL, the department had a significant teaching input on masters degree schemes in the departments of Psychology, Biology, Sociology, Engineering and the Management School. The CETL has permitted the opportunity for us to focus on improving postgraduate statistics, although in doing this, it has attracted an audience with both distinct and varied interests. We are thus presented with a challenge to achieve a balance between what is possible generically and what needs to be subject specific [1]. To extend our course provision for other teaching practice across the university we have taken several approaches:

- In the first instance, working closely with the staff from other departments, we have developed and deliver a diverse range of courses at Masters level. These include two core modules taught over twenty weeks to forty five students on the MScs in Social Psychology, Developmental Psychology and Psychological Research Methods that involve project-based work and SPSS practical sessions. From 2007/8, these modules will also departments and to promote innovative and excellent

be offered as compulsory elements of a new MSc in the Psychology of Hearing, Speech and Language.

- In the Department of Sociology four quantitative modules are taught on the MSc in Sociological Research Methods and on the MSc in Tourism. Finally, on the MA in Human Resource and Knowledge Management and on the MA in Human Resource development and consulting a twenty hour module is delivered to sixty students.

- We are expanding the use of web-based teaching by filming short course lectures and making videos that combine the lecturer, the slides and software demos with downloadable course notes which are available on the web for all Lancaster students and staff [2].

- The PSC website has a student resources page which provides a comprehensive list of additional resources in the practical application of statistical methods for students [3]. Students can therefore at their own pace and level of understanding, gain confidence in applying statistics to their own data.

- In collaboration with staff in the Biology department, a 'Data Analysis and Interpretation' course has been extended and fully updated from a five credit module to a twenty credit module and it is evident from both students and staff that there is popular demand for a further module in Bioinformatics to be offered from $2007 / 8$ which is currently in the final stages of approval.

- In collaboration with the Computing and Biology departments, we are also currently leading the development of two new MSc degree schemes in Bioinformatics and in Statistical Genomics which we plan to offer to students from 2008. With the Department of Accounting and Finance in the Management School, we have made a major contribution to a proposed MSc in Financial Statistics which is also awaiting university approval.

\section{(ii) Consultancy}

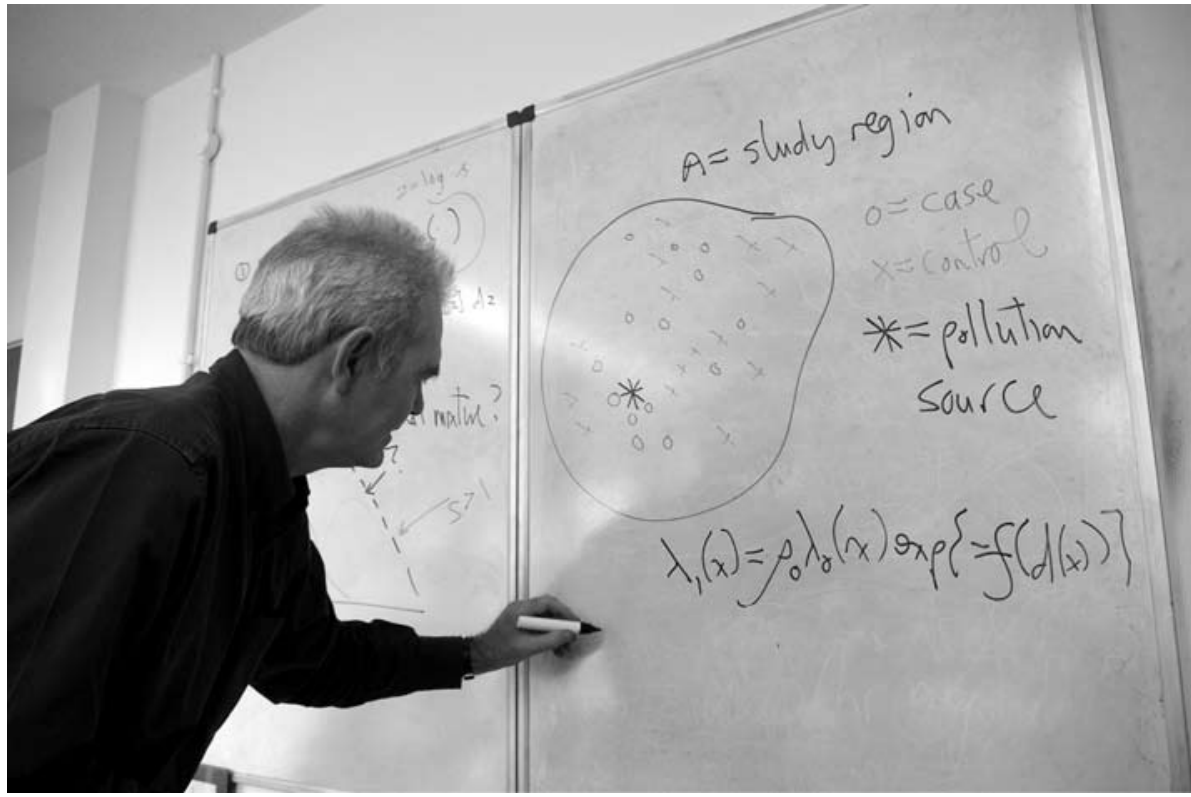

In addition to an outstanding research and teaching record, institutional support for postgraduate statistics training to students in other disciplines, Lancaster also has a centrally-resourced statistics service (amongst the strongest in the UK), established since 1985, to provide consultancy, mentoring and training courses to postgraduate students from all disciplines, staff and external clients. The appointment of the new CETL lecturers has enabled expansion of this service which is very popular and often oversubscribed.

Fig 2 - Short course delivered by a statistics expert at Lancaster 
The new building will include a much-needed and dedicated Consultancy Suite for these sessions.

The Consultancy Service is currently funded by ESRC and is open to all UK academics, providing help and guidance on statistical matters, including questionnaire design, statistical analysis of data, use of statistical packages, design of experiments and data display. A web-based appointment system is operated that can be accessed via the following link [4], with sessions available on Tuesday, Wednesday and Thursday afternoons from $2 \mathrm{pm}$ to $5 \mathrm{pm}$.

\section{(iii) Short Courses}

Recruitment of the new CETL staff has enabled us to both expand and extend the provision of short courses on offer from ten to twenty. These courses cover a wide range of statistical methods and applications that are relevant in many subject areas and are available to both Lancaster staff, students and external participants for a nominal fee. Appointment of a Web Officer to the CETL has enabled a full overhaul of the short courses website which is now fully equipped with an online, user-friendly course registration system [5]. For a list of courses currently available see [6].

Many courses have been oversubscribed this year with frequent requests from both internal and external students to run duplicate workshops on the most popular topics which include 'An Introduction to R', 'Structural Equation Modelling' and 'Atlas Ti'. The increased capacity provided by the lecture theatre and computer rooms in the new building will allow us to double enrolment numbers on courses available from 2008.

\section{"The PSC is now well on its way to becoming established as a unique postgraduate facility for statistics training both for specialist statisticians and non-specialists alike."}

Finally, in September 2006 the PSC hosted two successful and well-attended events that were available nationally to both staff and students. Firstly, a week long Graduate Training Programme (a joint RSS/EPSRC venture) where international experts provided inspiring courses on 'Event History Analysis' and an 'Introduction to Wavelets' and secondly, a two-day master class and workshop on 'Statistical Genomics'.

\section{Collaborative Projects}

In order to achieve our aim of engaging nationally with the training of postgraduate students in statistics and related skills, PSC members have been involved in the following activities: (i) With Other Departments within Lancaster University

- In 2006, a joint bid with the Dean of Arts and Social Sciences was successful in designating Lancaster to be one of eight ESRC Regional Training Centres to provide quantitative training for Social Scientists. This funding enables the PSC to host up to fifteen training days per year that are delivered by experts in the field and that are open at a national level, to postgraduate students, teachers of statistics, teachers of research methods and social science researchers. To date, we have hosted: a two day workshop on 'Teaching students quantitative methods using resources from the British Birth Cohorts', delivered by exerts from the Centre for Longitudinal Studies, and we are about to host, in conjunction with the Office for National Statistics, a workshop on the Survey Link Scheme, with particular emphasis on the development of interview questionnaires. Information on, and requests for, forthcoming specialist training courses can be viewed at the Research Development Initiative website [7].

- Earlier this year, together with staff from the departments of Educational Research and Psychology, we were successful in obtaining $£ 90 \mathrm{k}$ from the ESRC to fund the SIMPLE project (Statistical Instruction Modules with Purposeful Learning Emphasis). The project will provide online support materials for Psychology in Education students who are studying statistics and the environment will be publicly available as a reusable learning object at the end of the project.

- We are awaiting the outcome of a further joint bid to the Higher Education Academy led by National Teaching Fellow Scheme prize winners from the Centre for Enhancement of Learning and Teaching, and from the Geography department to support and develop training materials to enhance numeracy skills for nonquantitative undergraduate students.

\section{(ii) With Groups from Other Universities}

In striving to achieve our aim to engage nationally with the training of postgraduate students in statistics and related skills, members of the department have been successful in winning three EPSRC joint awards with other Higher Education (HE) institutions for mathematics postgraduate training.

- Firstly, Lancaster will be the lead institution on the NATCOR project (A National Taught Course Centre in Operational Research) which will provide training until 2011 in advanced Operational Research Skills for OR, MBA and Economics students (the scope of which will include statistics training).

- Secondly, Lancaster is one of fourteen partners in the MAGIC (Mathematical Access Grid Instruction and Collaboration) Consortium to provide national training in general mathematics skills (again including a statistical 
component). Funding from this project will provide the PSC with an access grid node which will greatly facilitate remote teaching in all areas of mathematics and statistics. Postgraduate Research students will be able to access, participate and interact with courses given by consortia members across the grid.

- Finally two members of the statistics group were awarded joint funding from the APTS (Academy for PhD Training in Statistics) programme which specifically targets training in advanced statistical methods and applied probability to first year PhD statisticians.

In addition to these activities, Lancaster statisticians are co-ordinating and directing one of six nodes of the ESRC National Centre for Research Methods. A large part of their remit is to offer low-cost training courses to social scientists, of which eight were available for the academic year 2006/7.

\section{Exploring Pedagogic Issues in Statistics}

As part of the CETL, funding is available to support experimentation with new technologies and methods of teaching. Some of the projects undertaken to date include:

- A research assistant in the department is investigating the use of Personal Response Systems (PRS) for teaching and learning of quantitative skills. In particular, PRS will be implemented using multiple choice questions which enable a whole class to take part anonymously, without the pressure of having to answer the question verbally. In the first instance, a trial of the PRS equipment and assessment of its potential as a learning tool will take place with a relatively small group of Masters students. The intended outcome is that this activity will not only motivate the students to become more active in their learning, but may also give the educator an overall idea in real time, of how well the class are coping with particular topics. If successful it is anticipated that PRS technology will be introduced to larger groups of learners.

- Other shorter projects have involved an evaluation of the impact, on both staff and students, of introducing a different form of assessment when teaching quantitative methods to Psychology Masters students [8] and an overview of the different approaches used by statistics teachers to overcome ambiguities that they are faced with when teaching statistics to non-statisticians [1].

- A future research project will assess the use of Personal Data Assistants (PDAs) on quantitative skills courses. A small group of students will be issued with PDAs for a trial period to facilitate mobile learning and monitor the effects of this on the student learning process.

\section{Concluding Remarks}

After an initial slow start to the project due to building constraints and recruitment issues, the PSC is now well on its way to becoming established as a unique postgraduate facility for statistics training both for specialist statisticians and non-specialists alike. The awarding of additional bids is enhancing the success of the PSC by increasing the possibilities for innovation and by encouraging deeper exploration of novel statistics teaching approaches to address the ever increasing diversity of learning needs within the student population and the requirements of different learning contexts within the HE community. We are looking forward to reporting future developments within the centre and envisage that sharing our practical knowledge in statistics pedagogy will both influence practice and raise the profile of statistics teaching across disciplines and across the wider HE community. Outcomes are disseminated via conference presentations, teaching seminars, teaching publications, workshops and the PSC website.

For more information about activities in the Postgraduate Statistics Centre please see our website

http://www.maths.lancs.ac.uk/psc or please contact me directly by email b.abram@lancaster.ac.uk.

\section{References}

1. Francis, B, Abram, B. and Peelo, M. (2007) "The Lancaster Postgraduate Statistics Centre CETL: building trust and statistical skills across disciplines." Proceedings of the CETL-MSOR Conference 2006 (in press).

2. Lancaster University, Centre for Applied Statistics, Elearning Short Courses webpage: http://www.cas.lancs.ac.uk/e-learning/index.php [Accessed 25 April 2007].

3. Lancaster University, Postgraduate Statistics Centre, Student Resources webpage: http://www.maths.lancs. ac.uk/psc/studentresources/

[Accessed 25 April 2007].

4. Lancaster University, Mathematics and Statistics Consultancy webpage: http://www.maths.lancs.ac.uk/ department/services/consulting [Accessed 25 April 2007].

5. Lancaster University, Centre for Applied Statistics webpage: http://www.cas.lancs.ac.uk/index.html [Accessed 25 April 2007].

6. Lancaster University, Centre for Applied Statistics, Short Courses webpage: http://www.cas.lancs.ac.uk/short_ courses/courselist.html [Accessed 25 April 2007].

7. Researcher Development Initiative (RDI), Events webpage: http://www.rdi.ac.uk/events.asp [Accessed 25 April 2007].

8. Kynn and Abram (2007) “Experiences in teaching masters psychology students : formative vs summative assessment." Proceedings of the CETL-MSOR Conference 2006 (in press). 